\title{
13
}

\section{The Role of a Teaching Center in Curricular Reform}

\author{
Constance Ewing Cook \\ University of Michigan
}

Instructional consultants can play a crucial role in curricular reform. They gather evaluation and assessment data about the current curriculum so that faculty decisions about improvements are based on empirical evidence. They organize and facilitate meetings and retreats at which faculty make curricular decisions, and they provide pedagogical expertise and resources to help with course design and enhancement. They also provide ongoing data for formative evaluation of the new curriculum. Examples from the University of Michigan's Center for Research on Learning and Teaching illustrate instructional consultants' contributions to the curricular reform process.

\section{INTRODUCTION}

The dean invited us to a faculty meeting to talk about the services that the Center for Research on Learning and Teaching (CRLT) could provide to her school. CRLT is the University of Michigan's teaching center, and it offers a wide array of services to all 19 schools and colleges on the Ann Arbor campus, including the professional school led by this dean. In preparation for the faculty meeting, the CRLT colleagues and I gathered examples of our work in UM's other schools and prepared handouts for the presentation.

At the meeting, we made our pitch, but the faculty expressed no interest in our services. The dean, who is a strong proponent of teaching and learning improvement, was clearly disappointed. She tried to engage her faculty by mentioning that the school could use our assistance with its new curricular reform effort. A senior professor expressed amazement, 
saying: "How can CRLT possibly help with curricular reform when no one there is familiar with our discipline?"

Unfortunately, faculty often assume that a teaching center cannot be of assistance with curricular reform. Survey data show that only $6.1 \%$ of faculty on campuses with teaching centers report that they consider the center helpful with course planning, and only a handful of faculty consider it a strong influence or a helpful source of assistance and feedback (Stark \& Lattuca, 1997, pp. 225, 229, and 272).

With occasional exceptions (e.g., Diamond; 1989, and Gaff, 1983), the literature on curricular reform rarely mentions that instructional consultants can play a useful role in the design and planning process (see Gardiner, 1992, for an overview of the curricular reform literature). Furthermore, most literature about teaching center programs and services does not mention curricular reform. That is true in spite of the fact that the mission of the Professional and Organizational Development Network in Higher Education (POD), the association of instructional consultants (also called faculty developers), is to foster professional development in three areas: faculty development, instructional development, and organizational development; and all three are integral to curricular reform (Diamond, 1988). As used here, the term curricular reform refers to the review and revision of existing sets of courses or the creation of new sets of courses that a program, department, or school/college offers to its students.

The purpose of this article is to present how instructional consultants can be useful in the curricular reform process. Since their contributions are often labor intensive, instructional consultants at a teaching center are more likely to be helpful than those unaffiliated with a center since centers usually provide professional colleagues and support staff to augment and facilitate individual consultants' efforts.

Typically, there are several obstacles to curricular reform, all of which instructional consultants can help overcome. First, curricular reform often flounders because faculty views about the current curriculum are based only on anecdotal information and hypothetical conjectures. There is no consensus about shortcomings or strengths in the current curriculum because there is no empirical data. In the absence of data showing otherwise, it is easy for colleagues opposed to change to contend that the current curriculum is adequate or for those who are eager for change to insist that change is essential. Even if everyone wants a change, the absence of commonly shared evaluation data makes it difficult to come to consensus about the direction the changes should take. Instruc- 
tional consultants can help by providing evaluation and assessment data for the current curriculum so that faculty decision making is empirically based.

Second, once faculty have the evaluation data in hand, curricular design and enhancement may not occur because of faculty time constraints. Faculty may be reluctant to come together to review the curriculum because it is such a lengthy and potentially contentious process. Instructional consultants can provide assistance with many aspects of faculty meetings and retreats so that faculty have less responsibility for planning and logistics, and meetings are more likely to be substantive, flow smoothly, and prove useful.

Once faculty have decided to craft new courses or enhance existing ones, they need resources and expertise to do it effectively. Otherwise, the efforts may fall short of the objectives. Instructional consultants can supply expertise on pedagogical issues to enhance student learning, and they can sometimes offer grants themselves or help make the case to other funders.

Finally, faculty frequently agree on revising a curriculum but then do no evaluation to make sure the new courses actually achieve the student learning goals they had agreed upon. Instructional consultants can help with ongoing data collection for formative evaluation.

\section{Evaluation of the Curriculum}

Evaluation of the curriculum typically begins with a request for help from an academic administrator, usually a dean, program director, or department chair. They come to CRLT with a problem, such as low enrollments or poor student retention. Instructional consultants often respond by asking that they engage a small group of faculty, perhaps a steering committee, who can help decide how to gather evaluative information about the current curriculum, including assessment of student learning.

Many consultants have expertise in survey research, so they may work with faculty and administrators to design a questionnaire that can be used for a broad review of curricular issues. Sometimes, they facilitate focus groups or interviews in order to gather enough information to design a good survey. Other times, the survey comes first, and when it is clear what the big picture is, they use focus groups or interviews to do indepth research on specific issues that the survey data identified as problematic. Instructional consultants can organize and facilitate data collection, transcribe the data, and then analyze and report on it. 
As part of their general evaluation of the curriculum, many faculty want to know what it is their students are actually learning. Accrediting agencies, state governments, and academic administrators also want to know. Therefore, instructional consultants at many teaching centers play a role in gathering outcomes assessment data for both internal and external curricular review.

\section{CASES From the University of Michigan}

Some stories from CRLT's work at the University of Michigan illustrate the many roles that instructional consultants can play.

\section{Department of Biology}

The Department of Biology in the College of Literature, Science, and the Arts requested CRLT assistance to evaluate its two key introductory courses. A faculty committee started by determining the specific learning goals it wanted the introductory course sequence to meet, and then the committee gathered data from a variety of sources to evaluate the extent to which the introductory courses were succeeding. CRLT helped the faculty review student ratings forms from previous years in order to identify areas of student dissatisfaction and then shape a questionnaire that was distributed to students in upper-level courses. Finally, CRLT conducted focus groups separately with undergraduate students, graduate student instructors (GSIs), and faculty members, for the purpose of exploring in depth some issues that the survey had shown to be problematic.

By the time the faculty convened to consider alternative curricular options, they had a shared understanding of the strengths and weaknesses of the current course sequence. Their students had said they wanted a course with more active learning and more connection between the lecture and lab. As one of the faculty leaders noted, these comments did not reveal anything new but helped prioritize the biggest problems and justify the expenditure of resources to solve one problem instead of another. As he put it, "After the CRLT report came out and it was in black and white . . . to not do anything would have been unthinkable because there it was: 500 students, 30 GSIs, and several professors saying that this format was very unsatisfying ..." (M. Amerlaan, personal communication with E. Brady, November 2, 1999).

After reviewing the results of the evaluation, the biology faculty created a single course to replace the former two-course sequence. They also added a discussion section in order to tie together the lecture and lab and 
provide more opportunity for students to take an active role in the learning process (University of Michigan Department of Biology, 1998). Now that the new introductory course is in place, student evaluations of the course are much more positive, on average, than for the courses they replaced (M. Amerlaan, personal communication with E. Brady, November 2, 1999).

After the conclusion of the curricular reform process, a biology faculty leader highlighted CRLT's importance in the change process: "What made it really work was having some people from CRLT come in who were neutral and who weren't seen to have any biases. It just cloaked the whole thing in a more true research aura as opposed to an attempt to forward individual interests" (M. Amerlaan, personal communication with E. Brady, November 2, 1999).

\section{A School that Wishes to Remain Anonymous}

The dean of this school was concerned about dissatisfaction expressed by some students of color, but he was unsure about what actions to encourage the faculty to take. He called in CRLT consultants, and they worked with a small faculty steering committee to develop a protocol of focus group questions. The focus groups included students of color, white students, and faculty-each meeting separately with CRLT facilitators of the same race or ethnicity. The focus group topics included both multicultural issues and other student concerns.

After completing the focus groups, CRLT sent the school a report summarizing the students' comments. Among them were insufficient multicultural content in the curriculum, faculty who did not know how to handle sensitive topics in class, and an absence of enough sense of community in the school.

In response to the report, the school invited CRLT consultants to design and facilitate a faculty retreat on multicultural teaching. At the retreat, faculty shared and discussed strategies for infusing multiculturalism into the curriculum and leading controversial discussions. Through role plays, CRLT's instructional consultants offered suggestions and gave faculty the opportunity to practice new approaches.

Since the retreat, there have been several changes at the school, including routine inclusion of more students on the curriculum committee and frequent discussion of ethics and values as part of regular faculty meetings. An accrediting team that recently visited the school rated it outstanding in its inclusion of multicultural materials in the curriculum and attention to issues of diversity. As one faculty member said, "The 
school works hard on multicultural issues pretty consistently now" (Personal communication, January 12, 2000).

\section{Landscape Architecture Program}

The faculty in the landscape architecture program of the School of Natural Resources and Environment wanted to gain an understanding of the reasons why incoming students had chosen the program and the skills and knowledge they hoped to acquire. They also wanted students' impressions of the current course sequencing and scheduling.

A CRLT instructional consultant worked with the faculty to design and conduct focus groups and surveys. She then provided the faculty with a report on student backgrounds and interests, as well as recommendations for change. The recommendations included better distribution of the workload from one semester to the next; making more connections among the courses, with each course building on the one before; and responding to the needs of nontraditional students whose schedules made them unable to take courses in a specific sequence.

At the conclusion of the curricular reform process, the program chair noted CRLT's value. He said it was the initial focus group and survey data that made it clear that curricular restructuring was necessary. He also cited the importance of the instructional consultant's role as a more objective observer: "By having someone outside the faculty come in and do this assessment, we likely got more honest responses. We were able to identify both small issues that we could address by simple fine tuning and better communication and the larger issues that required major restructuring." Finally, he commented on the value of involving students in curricular reform through surveys and focus groups: "Rather than students feeling left out or becoming worried that the program they were experiencing was somehow 'broken,' they felt like they were very much a part of the process and partners with faculty in making improvements" (R. Grese, personal communication, January 9, 2000).

\section{LESSONS LEARNED}

In each of the stories, faculty and administrators realized it was important to collect data about the current curriculum before rushing to judgment about making improvements. In each case, the data collection process (surveys, focus groups, and interviews) brought student voices into the decision-making process. The student data convinced skeptical faculty that change was really necessary, and it also offered information for priority setting by highlighting the biggest issues and pointing to directions 
for change. The involvement in data gathering by a neutral CRLT consultant lent credibility to the process and helped convince faculty of the veracity of the evidence.

\section{Course Design and Enhancement}

\section{Facilitation of Meetings and Retreats}

Collection of evaluation data about the curriculum often goes hand-inhand with retreat facilitation. Instructional consultants try to make sure that the former leads to the latter, as was the case in the biology, anonymous school, and landscape architecture examples above. It sometimes seems that the hardest part of curricular reform is getting faculty together to make decisions. Faculty time is at a premium, so it is important to make the decision-making process go smoothly. CRLT often helps achieve that objective.

An instructional consultant used the Delphi method to minimize the amount of time that history of art department faculty spent revising their curriculum. The Delphi method involves a decision tree, with a series of questionnaires, each building on the consensus developed by the one before (Stritter, Tresolini, \& Reeb, 1994; Tiberius, 1997). In the case of art history, the consultant summarized the responses after each round of the questionnaire and crafted new questions that slowly narrowed the options.

Initial questionnaires asked about competencies and knowledge that faculty consider integral to an art history major. By the time they arrived at the retreat, the faculty had already developed a consensus, and the retreat became an opportunity to brainstorm about ways to implement the objectives they had agreed upon. One issue that came up at the retreat was differentiation among 100-, 200-, 300-, and 400-level courses, so after the retreat, the consultant followed up by sending questionnaires about the competencies and knowledge faculty thought students should be expected to acquire at each course level.

Using grants competitions, CRLT also provided funding for the retreat, thereby giving the event more sense of importance. As one history of art professor noted, "There's kind of an impetus that is given to the project outside of the department - recognition and acknowledgment of its importance. . . It says that what you're interested in doing strikes other people as being important too. To have some of those 'dangling hooks'-outside visitors, meals - all of those things can help" (P. Simons, personal communication with E. Brady, November 17, 1999).

Over the years, CRLT has organized and facilitated a great number 
of faculty retreats for curriculum review. Instructional consultants have also reduced the amount of time that faculty have had to spend on the decision-making process by summarizing the retreat conversations and providing follow-up documents, as was done for history of art.

\section{Consultation on Pedagogy}

Some faculty object to curricular reform because they do not want to do course revisions and retooling. Instructional consultants can ease their workload by helping with pedagogical aspects of course design. Pedagogy is critical to the delivery of new courses and new curricula. Most faculty do not consider themselves pedagogical experts, but without attention to pedagogy, curricular reform may not accomplish the faculty's student learning goals.

Instructional consultants often give faculty advice about how to integrate critical thinking and active learning into new subject matter. For example, in the University of Michigan's extensive calculus reform project, the math department chair credited CRLT with helping the department incorporate cooperative learning into the curriculum. He said, "We had a consultant from CRLT . . . whose cooperative learning got students to talk to each other and explain their difficulties. Students come out with much more appreciation of mathematics as a useful discipline" (A. Taylor, personal communication, March 5, 1997).

Instructional consultants can also provide assistance with multicultural teaching and learning, such as fostering an inclusive classroom climate, teaching students with a variety of learning preferences or needs, and handling sensitive topics and emotional discussions in the classroom (e.g., Border \& Chism, 1992; Cook \& Sorcinelli, 1999; Kardia, 1998; Ouellett \& Sorcinelli, 1998). CRLT often provides assistance of this nature, as indicated in the anonymous school example above. Additionally, consultants can help with syllabus construction, research paper and examination design, grading practices, and a variety of other aspects of the instructional process. Many provide assistance with the use of instructional technology to foster student learning. As a result, it is common for academic units to call on CRLT consultants when they develop a new curriculum. For example, when the School of Nursing completed its curricular reform process and targeted specific faculty members to teach the new courses, it contracted with CRLT to help the faculty develop pedagogy that would best enhance student learning.

Beyond these generic pedagogy issues that can apply to any course or 
set of courses, many instructional consultants offer pedagogical expertise of a specialized nature. For example, they may have expertise on interdisciplinary course pedagogy or writing across the curriculum. With living-learning programs and community service-learning programs so popular on our campuses, instructional consultants often contribute expertise regarding course design for these programs as well.

\section{Funding for Curricular Reform}

CRLT administers several grant competitions, some of which fund broad curricular reform efforts involving large numbers of faculty in departments or programs. For instructional consultants without such resources, it is nonetheless possible to bolster the requests that faculty make to academic administrators.

Sometimes grants provide the equipment that faculty need in order to create new courses or new learning in existing courses. For example, when the School of Art and Design decided to add a computing curriculum, a CRLT grant funded a workroom where faculty could receive instruction on using computers, grade computer-based assignments, hone their computer skills, and develop course assignments and materials.

Grants can be used for faculty to collect their own data about curricular improvements. For example, a grant to a mathematics professor bought him out of some teaching so he could attend science and engineering classes to determine what mathematics the students needed for those classes. He then reported to departmental colleagues about how to provide better math service courses. Another grant funded faculty in psychology and social work to conduct a quasi-experimental study to evaluate the short-and long-term impact of community service courses in Detroit on their students' multicultural learning.

Grants sometimes fund faculty in several academic units to work together to develop interdisciplinary curricula for their students. For example, a CRLT grant to the School of Nursing provided funding to a faculty member who organized planning meetings for her colleagues, as well as faculty in the Schools of Social Work, Public Health, Dentistry, and Pharmacy. These units jointly developed opportunities for their students to learn about community-based health care.

Sometimes grants are used to bring in new expertise and help a department or program develop new courses or new components of existing courses. For example, a grant to a social work faculty member funded a project involving infusion of material about Asian Pacific islanders into 
the curriculum. The grant paid for stipends and travel to Ann Arbor for several Pan Asian experts, who then gave presentations and consulted individually with faculty to help them consider how they might incorporate new learning into their courses.

Finally, grants may be used to fund the development of new curricular modules that can be used in many courses. For example, a grant to an engineering professor helped him develop a website with ethics case studies to serve as a resource for all engineering faculty who incorporated ethics instruction into their courses. He offered a workshop to faculty colleagues to generate interactive cases that would add substance and new ethics topics to the website.

Faculty report that CRLT funding is especially useful in giving projects more importance than they would otherwise have. For example, CRLT gave a grant to a faculty member in the Medical School for creation of a videotape about cross-cultural communication, to be used for a required orientation program for first-year students. The project director commented:

\begin{abstract}
When you are awarded external funding in the Medical School, people sit up and take notice. In the case of my project, CRLT funding gave it both visibility and import. I think the fact that the dean has to sign off on the application is critical. I don't believe the program would have received the visible support it did or have been as successful as it was had I just strung together funds from [internal] sources . . . It was important for me to be able to tap technical expertise. I couldn't have done that without the legitimacy that CRLT lent to my project (L. Robins, personal communication, January 14, 2000).
\end{abstract}

Thus, CRLT funding for curricular improvements has importance far beyond its dollar value.

\title{
Formative Evaluation of the New Curriculum
}

There is not a single fix that solves all problems. Especially when there is a dramatic change in instructional goals and methods, it is wise to collect data over an extended period-both for the purpose of making continual course improvements and also for determining the extent to which individual courses continue to incorporate the new student learning goals. A teaching center can be helpful with ongoing data collection. 


\section{Department of Mathematics}

The Department of Mathematics began its process of revising introductory calculus instruction nearly a decade ago. Among the new instructional goals were incorporation of cooperative learning both in the classroom and in homework teams; realistic, open-ended problems that encourage analysis and problem solving skills; and the use of writing as a learning tool.

CRLT has worked with math over a period of many years to evaluate the extent to which the new courses are achieving their goals. For this purpose, CRLT has used midterm student feedback (MSF), also called Small Group Instructional Diagnosis (SGID). In an MSF, a CRLT consultant asks students what is going well in the course and what would help them learn more. The consultant synthesizes student comments and provides them confidentially to the instructor-in the middle of the term when it is still possible to make improvements.

Ordinarily, it is individual instructors who utilize MSFs for teaching improvement, but in calculus, course coordinators have used them term after term for most sections of the multi-sectioned courses in order to get a general sense of student satisfaction and self-reports of learning. The MSF data have led to frequent course revisions. For example, MSFs indicated that students did not understand the new learning goals, so the coordinators urged instructors to keep students informed about goals throughout the term. They also incorporated explicit learning goals into course reading assignments in order to maximize student understanding of the new approach to calculus instruction (Black, 1998). The math experience shows that curricular reform is not a one-time process, and faculty continue to need assistance from instructional consultants.

\section{College of Engineering}

The College of Engineering decided to assess the extent to which its students were mastering 11 types of knowledge and competencies that a curriculum committee had determined to be essential elements of the undergraduate curriculum. Since most of the eleven were taught in a wide variety of courses, not just one, the college wondered which courses were teaching what. The faculty decided to include in the end-of-course student ratings forms questions about self-reports of learning in all 11 areas. CRLT provided assistance with development of the instrument and with data analysis and reporting. CRLT also aided the college in creating survey instruments for graduating seniors and alumni in order to further assess students' perceptions of their learning. 
The college presented a summary of this data to the team from the Accreditation Board for Engineering and Technology (ABET) as it conducted its site visit for reaccreditation. The associate dean later sent a positive report to CRLT, saying, "The evaluators seemed impressed with the assessment plans . . . and they very much liked the way the course evaluations were revamped" (J.W. Jones, personal communication, November 23, 1999). Long term, it will be helpful for the college to have the course-by-course data, as well as the seniors and alumni data, to make sure that the knowledge and competencies the faculty agreed to incorporate into the curriculum continue to be taught.

\section{Some Challenges for Instructional Consultants}

It is clear that instructional consultants add value to the curricular reform process, and for those of us in the business of improving teaching and learning, there is a lot of satisfaction to be gained. However, involvement in curricular reform carries its own challenges.

\section{Workload}

One of the challenges is workload. Curricular reform services, such as focus groups and retreats, are labor intensive. Teaching centers require considerable staffing, both professional and support staff, to supply significant amounts of assistance. However, even with considerable staffing, it is still impossible for a relatively large center like CRLT to satisfy all the demands for its services. It is necessary, therefore, to pick one's clients carefully-perhaps by choosing projects that impact large numbers of students, or perhaps by choosing high visibility projects that will create more of a culture of teaching on campus.

\section{Unused Data}

A second, and related, challenge is that of unused data. For example, the interim director of an important campus program asked CRLT to evaluate the academic rigor of his program and determine how to improve student learning. Many surveys and focus groups later, we completed the project and delivered the data to the interim director so he could present it to the permanent director as he came on board. Two years later, the new director admitted that he never used the CRLT data at all. As a result, we now realize that perhaps we should not agree to do evaluations for interim administrators. It might be better to wait until someone is in place that can implement changes-if, indeed, the data indicates that 
change is necessary. Furthermore, it is problematic to do evaluations for units where faculty are split into factions because the chance of effecting real change are so slim. Sometimes, intelligence gathering about the academic unit can help to determine whether that unit is one that should have priority in the teaching center's list of projects.

\section{Communication about Consultant Role}

A third challenge is the one mentioned at the start of this article, namely, the challenge of communicating to faculty about the role of instructional consultants in curricular reform. Word about a center's contribution to one department's curricular reform spreads slowly to other departments because there is a Catch-22 to instructional consulting services: A teaching center can only succeed if its contribution occurs behind the scenes, with faculty taking credit for their own success. If consultants claim credit for curricular and other improvements, faculty may be reluctant to use their services in the future. The Catch- 22 occurs because a teaching center needs to have visibility in order to capture enough university resources to do the work that is requested and in order to stimulate enough faculty interest to have a ready market for its services.

Instructional consultants bring considerable value to the reform process and should find ways to inform deans, department chairs, and faculty about the contributions they can make. Consultants make reform more likely and more fruitful by structuring the process and supplying the labor, resources, and pedagogical expertise that busy faculty and administrators may be unable or unwilling to supply themselves. Instructional consultants make it possible for students to learn what the faculty really want them to know.

\section{ACKNOWLEDGments}

The author wishes to acknowledge the work of Elizabeth Brady, graduate student in the Center for the Study of Higher and Postsecondary Education, University of Michigan. As part of her independent student project, she conducted interviews of selected faculty who received CRLT grants for curricular reform.

\section{References}

Black, B. (1998). Using the SGID method for a variety of purposes. In M. Kaplan \& D. Lieberman (Eds.), To improve the academy, 17, 245-262. Bolton, MA: Anker. 
Border, L..B. \& Chism, N.V.N. (1992). Teaching for diversity. New Directions for Teaching and Learning, No. 49. San Francisco, CA: Jossey- Bass.

Cook, C. E., \& Sorcinelli, M. D. (1999). Building multiculturalism into teaching development programs. AAHE Bulletin, 51 (7) 3-6.

Diamond, R. M. (1988). Faculty development, instructional development, and organizational development: Options and choices. In E. C. Wadsworth (Ed.), $A$ bandbook for new practitioners (pp. 9-11). Stillwater, OK: New Forums Press.

Diamond, R. M. (1989). Designing and improving courses and curricula in higher education: A systematic approach. San Francisco, CA: Jossey-Bass.

Gaff, J. (1983). General education today: A critical analysis of controversies, practices, and reforms. San Francisco, CA: Jossey-Bass.

Gardiner, L. F. (1992). Designing a college curriculum: Overviewe, planning aids, and selected resources. Professional Resource No. 4 (copyright by Gardiner).

Kardia, D. (1998). Becoming a multicultural faculty developer: Reflections from the field. In M. Kaplan \& D. Lieberman (Eds.), To improve the academy, 17, (15-34). Bolton, MA: Anker.

Ouellett, M. L., \& Sorcinelli, M. D. (1998). TA training: Strategies for responding to diversity in the classroom. In M. Marincovich, H. Prostko, \& F. Stout (Eds.), The professional development of graduate teaching assistants. Bolton, MA: Anker.

Stark, J. S., \& Lattuca, L. R. (1997). Shaping the college curriculum: Academic plans in action. Needham Heights, MA: Allyn \& Bacon.

Stritter, F. T., Tresolini, C. P., \& Reeb, K. G. (1994). The Delphi technique in curriculum development. Teaching and Learning in Medicine, 6 (2), 136-141.

Tiberius, R. (1997). Small group methods for collecting information from students. In K. T. Brinko \& R. J. Menges (Eds.), Practically speaking: A sourcebook for instructional consultants in bigher education (pp. 53-63). Stillwater, OK: New Forums Press.

University of Michigan Department of Biology. (1998). Alumni Nezesletter, p. 5. 
Contact:

Constance Ewing Cook

Director, Center for Research on Learning and Teaching

Associate Professor of Higher Education

Adjunct Associate Professor of Political Science

University of Michigan

$3300 \mathrm{SEB}$

Ann Arbor, MI 48109-1259

(734) $763-0159$

(734) 647-3600 (Fax)

http://www.umich.edu/ crltmich

Email:Cecook@umich.edu

Constance Ewing Cook is Director of the Center for Research on Learning and Teaching (CRLT) at the University of Michigan-Ann Arbor campus. She is also Associate Professor in the Center for the Study of Higher and Postsecondary Education (CSHPE), the higher education program at Michigan, and teaches a graduate course on improving teaching and learning in higher education. Additionally, as a political scientist, she teaches a course on public policy in higher education and is the author of a recent book on the topic: Lobbying for highereducation: How colleges and universities influence federal policy (Vanderbilt University Press, 1998). 